DOI: 10.25557/0031-2991.2020.01.124-127

(c) Коллектив авторов, 2020

УДК 611.611:612.127.2:616.379-008.64-092.4

Филинова С.О., Жариков А.Ю., Мазко О.Н., Макарова О.Г., Баландович Б.А.

\title{
Показатели прооксидантного и антиоксидантного статусов в почках крыс при экспериментальном сахарном диабете
}

ФГБОУ ВО «Алтайский государственный медицинский университет» Минздрава России, 656038 , г. Барнаул, Россия, просп. Ленина, д. 40

Цель исследования - изучение активности процесса свободнорадикального окисления в почках крыс в условиях экспериментального сахарного диабета. Методика. Исследование выполнено на 25 самцах крыс Вистар. Животные были разделены на 2 группы: группа интактных крыс (контроль) и группа животных с сахарным диабетом (опыт) по 12 и 13 особей соответственно. Моделирование сахарного диабета осуществляли внутрибрюшинным введением стрептозотоцина (65 мг/кг). Для селективного моделирования сахарного диабета II типа крысам группы «опыт» предварительно вводили внутрибрюшинно 1 мл раствора цитофлавина (из расчета дозы никотинамида 115 мг/кг). Группе интактных крыс аналогичным способом вводили 1 мл физиологического раствора. На 28-е сут эксперимента животных декапитировали под эфирным наркозом с целью изучения активности процесса свободнорадикального окисления в почках. В тканях почек определяли концентрацию тиобарбитуратреактивных продуктов окисления жирных кислот, оценивали общую прооксидантную активность по интенсивности окраски флуоресцентного комплекса, образующегося при взаимодействии продуктов перекисного окисления ТВИН-80 с тиобарбитуровой кислотой. Определяли активность антиоксидантных ферментов: каталазы, супероксиддисмутазы и глутатионпероксидазы. Активность каталазы определяли по подавлению ферментом окисления молибдата натрия перекисью водорода. Активность супероксиддисмутазы оценивали по содержанию в пробе нитроформазана - окрашенного продукта восстановления нитротетразолия синего супероксидными радикалами. Определяли содержание неокисленного глутатиона (маркера активности глутатионпероксидазы) по цветной реакции с реактивом Эллмана. Результаты. В ходе исследования было установлено увеличение концентрации тиобарбитуратреактивных продуктов окисления жирных кислот, основным представителем которых является малоновый диальдегид, увеличение общей прооксидантной активности, а также активности глутатионпероксидазы и супероксиддисмутазы. Заключение. В условиях экспериментального сахарного диабета наблюдаются признаки выраженного оксидативного стресса в почечной ткани, о чем свидетельствует увеличение концентрации тиобарбитуратреактивных продуктов окисления жирных кислот и общей прооксидантной активности, а также повышение активности антиоксидантных ферментов.

Ключевые слова: сахарный диабет; оксидативный стресс; нефропатия.

Для цитирования: Филинова С.О., Жариков А.Ю., Мазко О.Н., Макарова О.Г., Баландович Б.А. Показатели прооксидантного и антиоксидантного статусов в почках крыс при экспериментальном сахарном диабете. Патологическая физиология и экспериментальная терапия. 2020; 64(1): 124-127.

DOI: 10.25557/0031-2991.2020.01.
Для корреспонденции: Филинова Светлана Олеговна, e-mail: svetulya1511@mail.ru
Финансирование. Исследование не имело спонсорской поддержки.
Конфликт интересов. Авторы заявляют об отсутствии конфликта интересов.
Поступила 17.09.2019
Принята к печати 16.01.2020
Опубликована 25.02 .2020

Filinova S.O., Zharikov A.Yu., Mazko O.N., Makarova O.G., Balandovich B.A.

\section{Indexes of pro- and antioxidant status in kidneys of rats with experimental diabetes mellitus}

Altai State Medical University,

Prospekt Lenina 40, Barnaul 656038, Russia

The aim of the study was to assess indexes of pro- and antioxidant status of the kidneys in experimental diabetes mellitus. Methods. The study was performed on 25 Wistar male rats in compliance with requirements of the Rules for Carrying Out Work using Experimental Animals. The animals were divided into two groups, a group of intact rats (control) and a diabetic group (experiment) containing 12 and 13 rats, respectively. Diabetes mellitus was modeled with an injection of streptozotocin (65 mg/kg, i.p.). For more specific modeling of type 2 diabetes, the rats of the experimental group received a solution of cytoflavin at a dose equivalent to nicotinamide 115 mg/ $\mathrm{kg}$, i.p. At 28 days of the experiment, rats were decapitated under ether anesthesia, and activity of free radical oxidation (FRO) was studied in the kidneys. The following indexes were determined in the kidney tissue: concentration of thiobarbiturate- reactive fatty acid oxidation products (TPBP); total pro-oxidant activity by color intensity of the fluorescent complex formed by the interaction of TWEEN-80 
peroxidation products with thiobarbituric acid; activities of antioxidant enzymes, catalase (CAT), superoxide dismutase), and glutathione peroxidase (GPO). CAT activity was measured by the CAT inhibition of sodium molybdate oxidation with hydrogen peroxide. SOD activity was measured by the content of nitroformazan, a colored product of nitrotetrazolium reduction with superoxide radicals. The marker of GPO activity, unoxidized glutathione, was measured by the color reaction with Ellman's reagent. Results. The study findings included increased TBP represented primarily by malonic dialdehyde, as well as increased TPOA (total pro-oxidant activity), and GPO and SOD activities in diabetic kidneys. Conclusion. Experimental diabetes mellitus was associated with pronounced oxidative stress in the kidney tissue, as evidenced by increased TPBP and TPOA, as well as by increased activities of antioxidant enzymes.

Keywords: diabetes; oxidative stress; nephropathy.

For citation: Filinova S.O., Zharikov A.Yu., Mazko O.N., Makarova O.G., Balandovich B.A. Indicators prooxidant and antioxidant status in kidneys of rats with experimental diabetes. Patologicheskaya Fiziologiyai Eksperimental 'naya terapiya. (Pathological Physiology and Experimental Therapy, Russian Journal). 2020; 64 (1): 124-127. (in Russian).

DOI: $10.25557 / 0031-2991.2020 .01 .124-127$

For correspondence: Filinova S.O., e-mail: svetulya1511@mail.ru

Conflict of interest. The authors declare no conflict of interest.

Acknowledgment. The study had no sponsorship.

Received 17.09.2019

Accepted 16.01.2020

Published 25.02.2020

Распространенность сахарного диабета (СД) во всем мире стремительно растет [1]. Наибольшая опасность СД связана с осложнениями, обусловленными развитием так называемых диабетических ангиопатий, в том числе сосудистых диабетических нефропатий (ДН). Нефропатия развивается приблизительно у 20,1\% пациентов с СД 1 типа и 6,3\% пациентов с СД 2 типа [2]. Поиск эффективных методов коррекции диабетической нефропатии остается актуальной медицинской задачей.

Принято считать, что хроническая гипергликемия при СД способствует продукции реактивных форм кислорода, которые, в свою очередь, обусловливают повреждение мембран и органелл клеток [3, 4]. Ряд исследователей указывает на то, что такие процессы происходят и в почках при СД, инициируя каскад биохимических реакций, приводящих к повреждению сосудистой стенки и развитию нефропатии $[5,6]$. В то же время биохимическая картина оксидативного стресса в почечной ткани при СД охарактеризована недостаточно, что ограничивает возможности поиска новых методов медикаментозной коррекции. Выявление особенностей формирования прооксидантного и антиоксидантного статусов в нефроцитах при СД может способствовать определению вектора поиска новых фармакологических подходов к коррекции диабетической нефропатии.

Цель исследования - изучение активности процессов свободнорадикального окисления в почках крыс в условиях экспериментального сахарного диабета.

\section{Методика}

Все процедуры, связанные с содержанием и использованием животных, проводили с соблюдением директив Европарламента и Совета европейского со- юза (2010/63/EU), регламентирующих использование животных в научных целях. Экспериментальные протоколы рассмотрены и утверждены этическим комитетом ФГБОУ ВО Алтайского государственного медицинского университета.

Эксперименты выполнены на 25 самцах крыс Вистар 2-х-3-х месячного возраста, массой 270-300 г. Крысы на протяжении периода исследований находились в индивидуальных «метаболических» клетках, приспособленных для сбора мочи, в условиях свободного доступа к воде и пище. Животные были разделены на 2 группы: группа интактных крыс (инт.) и группа «опыт» (опыт.) по 12 и 13 особей соответственно. В группе опыт моделировали СД внутрибрюшинным однократным введением 1 мл раствора стрептозотоцина в цитратном буфере из расчета 65 мг/кг. В соответствии с современными представлениями об особенностях моделирования стрептозотоцинового СД для селективного моделирования СД ІІ типа крысам группы «опыт» предварительно вводили внутрибрюшинно раствор цитофлавина из расчета дозы никотинамида 115 мг/кг [7]. Группе интактных крыс аналогичным способом вводили 1 мл физиологического раствора.

На 28-е сут эксперимента животных декапитировали под эфирным наркозом, извлекали почки и промывали их физиологическим раствором. Активность процессов свободно-радикального окисления (СРО) оценивали по совокупности показателей оксидантного и антиоксидантного статусов $[8,9]$. Показатели оксидантного статуса определяли в гомогенате коркового вещества почек. Суммарный показатель концентрации всех прооксидантов и свободно-радикальных метаболитов, общую прооксидантную активность (ОПА) оценивали по интенсивности окраски флуоресцентного комплекса, образующегося 
при взаимодействии продуктов перекисного окисления ТВИН-80 с тиобарбитуровой кислотой. Дополнительно определяли концентрацию в ткани малонового диальдегида (МДА) и других тиобарбитуратреактивных продуктов окисления жирных кислот (ТБРП).

В гомогенате коркового вешества почек исследовали активность антиоксидантной системы. Общая антиоксидантная активность (ОАА) оценивалась как интегративный показатель активности всех ферментных и неферментных факторов нейтрализации свободных радикалов (по степени угнетения $\mathrm{Fe}^{2+}$ /аскорбатзависимого окисления ТВИН-80 гомогенатом ткани) [9]. Определяли активность антиоксидантных ферментов: каталазы (КАТ), супероксиддисмутазы (СОД) и глутатионпероксидазы (ГПО). Активность КАТ определяли по подавлению ферментом окисления молибдата натрия перекисью водорода (перекись водорода окисляет молибдат натрия с образованием окрашенных продуктов, разложение перекиси водорода под действием каталазы уменьшает интенсивность окрашивания проб). Активность СОД оценивали по содержанию в пробе нитроформазана, окрашенного продукта восстановления нитротетразолия синего супероксидными радикалами. Для выявления маркера активности ГПО определяли активность неокисленного глутатиона по цветной реакции с реактивом Эллмана. Расчет активности ферментов проводили относительно контрольной пробы (вода) и выражали в процентах [10].

Статистическую обработку результатов проводили с использованием компьютерной программы Statistica 12.0. Результаты представлены медианой (Me) и межквартильным размахом $(25 \%, 75 \%)$. Различия показателей между группами определяли с использованием непараметрического U-критерия Манна-Уитни. Результаты считали статистически значимыми при $p<0,05$.

\section{Результаты и обсуждение}

Результаты проведенных экспериментов показали, что в условиях моделирования стрептозотоцинового СД в почках подопытных крыс развивался выраженный оксидативный стресс, о чем свидетельствовали характерные биохимические признаки. У животных с СД по истечению 4 нед наблюдалось увеличение содержания ТБРП в гомогенате почек в 1,4 раза по сравнению с уровнем у интактных животных: $8,5[8,5 ; 8,8]$ мкмоль и $6,1[5,4 ; 6,9]$ мкмоль соответственно $(p=0,000001)$. Параллельно с этим имело место увеличение ОПА с 65,1 $[63,4 ; 68,0] \%$ у интактных крыс до $70,7[68,6 ; 71,2] \%$ в группе животных с СД ( $p=0,00087)$.

На этом фоне фиксировались существенные изменения показателей антиоксидантного статуса в почках крыс. Активность ГПО при экспериментальном СД статистически значимо увеличивалась (в 1,2 раза) относительно группы интактных животных: 45,3 [42,1; 47,8] \% и $38,5[25,2 ; 41,6] \%$ соответственно ( $p=0,00568)$. Отмечался также рост активности СОД с $18,2[13,0 ; 18,5] \%$ у интактных крыс до 23,1 [18,4; 26,0] \% при СД ( $p=0,0272)$. Активность КАТ, напротив, снижалась (в 1,4 раза) у животных с СД по сравнению с интактными животными: 10,3 [6,8; $13,0] \%$ и $14,4(10,2 ; 15,6) \%$ соответственно $(p=0,0262)$. Параллельно, в условиях экспериментального СД наблюдался рост ОАА на $11 \%$ по сравнению с группой интактных крыс: 46,3 [43,6; 46,9] \% против 41,7 [40,2; 43,3] соответственно $(p=0,00562)$.

Обсуждая полученные результаты, отметим, что, как известно, основным представителем ТБРП является малоновый диальдегид, являющийся биохимическим маркером перекисного окисления клеточных мембран [8]. Поэтому существенное увеличение концентрации ТБРП в тканях почек крыс с экспериментальным СД может свидетельствовать о повреждении мембран нефроцитов активными формами кислорода, накапливающимися в почках на фоне гипергликемии. Кроме того, в ходе исследования было зафиксировано статистически значимое увеличение ОПА. Как известно, ОПА - это показатель оксидативного статуса, который соответствует сумме всех прооксидантов и свободно-радикальных метаболитов, рост его указывает на усиление процессов окисления и истощение защитных антиоксидантных механизмов.

Анализ динамики активности ГПО, СОД и КАТ указывает на активацию антиоксидантной защиты в почках, которая, по-видимому, носит компенсаторный характер, направленный на нейтрализацию накапливающихся активных форм кислорода (АФК). В первую очередь об этом свидетельствует значительный рост активности главного антиоксидантного энзима глутатионпероксидазы. Данный фермент участвует в нейтрализации наиболее агрессивной АФК - гидроксильного радикала (“ОН) [11]. Как следствие, логично предположить, что в условиях экспериментального СД в почках происходит образование большого количества именно таких радикалов, что определяет высокую интенсивность и агрессивность свободнорадикального окисления в органе при СД.

Кроме того, наблюдалось увеличение активности СОД - фермента, одновалентно восстанавливающего супероксид до $\mathrm{H}_{2} \mathrm{O}_{2}$ [12]. Функции ферментов СОД и КАТ тесно взаимосвязаны, поскольку образующаяся в процессе дисмутации супероксида перекись водорода впоследствии инактивируется каталазой [11]. Поэтому логично было ожидать увеличение активности и 
каталазы. Однако ее активность относительно интактных крыс при экспериментальном СД, напротив, снижалась. Не исключено, что на 4-й нед развития патологии еще формируются начальные этапы включения антиоксидантной системы, когда клеточный ответ направлен на инактивацию посредством ГПО наиболее агрессивных АФК и трансформацию их в менее активные посредством СОД с последующей нейтрализацией под действием КАТ, что, по-видимому, может происходить в более поздние по времени периоды.

Таким образом в условиях экспериментального сахарного диабета наблюдаются признаки выраженного оксидативного стресса в почечной ткани, о чем свидетельствует рост показателей прооксидантного статуса при сопутствующем компенсаторном увеличении активности основных антиоксидантных ферментов.

\section{Литература}

1. Yao L., Li L., Li X., Li H., Zhang Y., Zhang R.et al. The antiinflammatory and antifibrotic effects of Coreopsis tinctoria Nutt on high-glucose-fat diet and streptozotocin-induced diabetic renal damage in rats. BMC Complement Altern. Med. 2015; 15: 314.

2. Дедов И.И., Шестакова М.В., Викулова О.К. Эпидемиология сахарного диабета в Российской Федерации: клинико-статистический анализ по данным федерального регистра сахарного диабета. Сахарный диабет. 2017; 20(1): 13-41.

3. Tan A., Forbes J., Cooper M. AGE, RAGE, and ROS in diabetic nephropathy. Semin Nephrol. 2007; 27(2): 130-43.

4. Zhang S., Xu H., Yu X., Wang Y., Sun F., Sui D. Simvastatin ameliorates low-dose streptozotocin-induced type 2 diabetic nephropathy in an experimental rat model. Int. J. Clin. Exp. Med. 2015; 8(4): 6388-96.

5. Шишко О.Н., Мохорт Т.В., Константинова Е.Э. Цапаева Н.Л, Моссе К.А. Роль эндотелиального фактора роста сосудов в патогенезе диабетической нефропатии. Медицинский журнал. 2013; 1(43): 132-5.

6. Soliman A.M., Mohamed A.S., Marie M.S. Echinochrome pigment attenuates diabetic nephropathy in the models of type 1 and type 2 diabetes. Diabetes mellitus. 2016; 19(6): 464-70.

7. Спасов А.А., Воронкова М.П., Снигур Г.Л., Чепляева Н.И., Чепурнова М.В. Экспериментальная модель сахарного диабета типа 2. Биомедицина. 2011; (3): 12- 8.

8. Брюханов В.М., Зверев Я.Ф., Лампатов В.В. Жариков А.Ю., Талалаева О.С. и др. Методы доклинического (экспериментального) исследования влияния лекарственных средств на функцию почек. Новосибирск; Гео: 2013.

9. Зверев Я.Ф., Брюханов В.М., Талалаева О.С., Лампатов В.В., Жариков А.Ю. и др. О роли процессов свободно-радикального окисления в развитии экспериментального нефролитиаза. Нефрология. 2008; 12(1): 58-63.
10. Рытикова О.С., Брюханов В.М., Зверев Я.Ф., Госсен И.Е. Роль перекисного окисления липидов в патогенезе непродолжительной ишемии почки в эксперименте. Нефрология. 2004; 8(4): 115-6.

11. Луцкий М.А., Куксова Т.В., Смелянец М.А., Лушникова Ю.П. Свободнорадикальное окисление липидов и белков - универсальный процесс жизнедеятельности организма. Усnехи современного естествознания. 2014; 12(1): 24-48.

12. Ratnam DV, Ankola DD, Bhardwaj V, Sahana DK, Kumar MN. Role of antioxidants in prophylaxis and therapy: A pharmaceutical perspective. J Control Release. 2006; 113(3): 189-207.

\section{References}

1. Yao L., Li L., Li X., Li H., Zhang Y., Zhang R. et al. The anti-inflammatory and antifibrotic effects of Coreopsis tinctoria Nutt on high-glucose-fat diet and streptozotocin-induced diabetic renal damage in rats. BMC Complement Altern. Med. 2015; 15: 314.

2. Dedov I.I., Shestakova M.V., Vikulova O.K. Epidemiology of diabetes mellitus in Russian Federation: clinical and statistical report according to the federal diabetes registry. Sakharnyy diabet. 2017; 20(1): 13-41. (In Russian)

3. Tan A., Forbes J., Cooper M. AGE, RAGE, and ROS in diabetic nephropathy. Semin Nephrol. 2007; 27(2): 130-43.

4. Zhang S., Xu H., Yu X., Wang Y., Sun F., Sui D. Simvastatin ameliorates low-dose streptozotocin-induced type 2 diabetic nephropathy in an experimental rat model. Int. J. Clin. Exp. Med. 2015; 8(4): 6388-96

5. Shyshko O.N., Mokhort T.V., Konstantinova E.E., Tsapaeva N.L., Mosse K.A. The role of vascular endothelial growth factor in pathogenesis of diabetic nephropathy. Meditsinskiy zhurnal. 2013; 1(43): 132-5. (In Russian)

6. Soliman A.M., Mohamed A.S., Marie M.S. Echinochrome pigment attenuates diabetic nephropathy in the models of type 1 and type 2 diabetes. Diabetes mellitus. 2016; 19(6): 464-70.

7. Spasov A.A., Voronkova M.P., Snigur G.L., Cheplyaeva N.I., Chepurnova M.V. Experimental model of a type 2 diabetes. Biomedicina. 2011; (3): 12-18. (In Russian)

8. Bryukhanov V.M., Zverev Ya.F., Lampatov V.V. Zharikov A.Yu., Talalaeva O.S. et al. Methods of preclinical (experimental) study of the effect of drugs on renal function [Metody doklinicheskogo (eksperimental'nogo) issledovaniya vliyaniya lekarstvennykh sredstv na funktsiyu pochek]. Novosibirsk; Geo; 2013. (In Russian)

9. Zverev Ya.F., Bryukhanov V.M., Talalaeva O.S., Lampatov V.V., Zharikov A.Yu., et al. On the role of processes of free radical oxidation in the development of experimental nephrolithiasis. Nefrologiya. 2008; 12(1): 58-63. (In Russian)

10. Rytikova O.S., Bryukhanov V.M., Zverev Ya.F., Gossen I.E. The role of lipid peroxidation in pathogenesis of kidney ischemia of short duration in experiment. Nefrologiya. 2004; 8(4): 115-6. (In Russian)

11. Lutsky M.A., Kuksova T.V., Smelyanets M.A., LushnikovaY.P. Lipid and protein free-radical oxidation as a universal vital process of the organism. Uspekhi sovremennogo estestvoznaniya. 2014; 12(1): 24-48.

12. Ratnam D.V., Ankola D.D., Bhardwaj V., Sahana D.K., Kumar M.N. Role of antioxidants in prophylaxis and therapy: A pharmaceutical perspective. J Control Release. 2006; 113(3): 189-207.

\section{Сведения об авторах:}

Филинова Светлана Олеговна, преподаватель каф. фармакологии, ФГБОУ ВО «Алтайский государственный медицинский университет» Минздрава России, e-mail: svetulya1511@mail.ru;

Жариков Александр Юрьевич, доктор биол. наук, доцент, зав. каф. фармакологии, e-mail: zharikov_a_y@mail.ru;

Мазко Олеся Николаевна, канд. биол. наук, доцент каф. фармакологии, e-mail: olesia.mazko@yandex.ru;

Макарова Олеся Геннадьевна, канд. фарм. наук, доцент каф. фармации, e-mail: olesia552@mail.ru;

Баландович Борис Анатольевич, доктор мед. наук, проф. каф. гигиены, основ экологии и безопасности жизнедеятельности, e-mail: dr.balandovich@mail.ru 